\title{
Characteristics of patients
}

\begin{tabular}{|c|c|c|}
\hline & Children $(\mathbf{N}=49)$ & Adult $(\mathbf{N}=22)$ \\
\hline Age - yr & & \\
\hline Mean & 8.24 & 31.33 \\
\hline Median & 8.0 & 30.0 \\
\hline Gender - no. (\%) & 29 & 9 \\
\hline Male & 20 & 13 \\
\hline Female & 2.5 & 1.0 \\
\hline Mean tonsil size - Grade & & \\
\hline
\end{tabular}

*Grading Scale
A. Tonsil 0: Tonsils fit within tonsillar fossa
B. Tonsil 1+: Tonsils $<25 \%$ of space between pillars
C. Tonsil 2+: Tonsils $<50 \%$ of space between pillars
D. Tonsil 3+: Tonsils $<75 \%$ of space between pillars
E. Tonsil $4+$ : Tonsils $>75 \%$ of space between pillars 


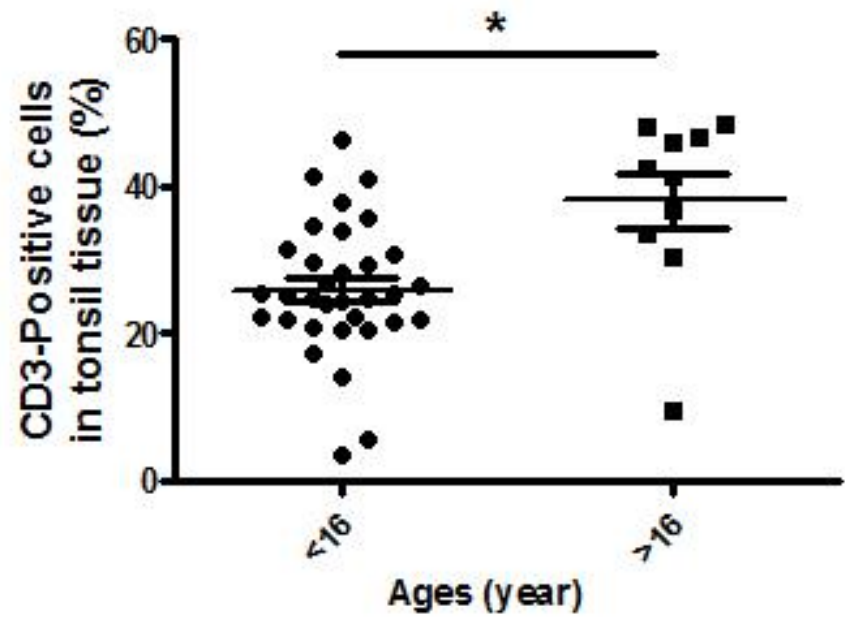

Level of CD3-positive cell in tonsil tissues with hypertrophy 


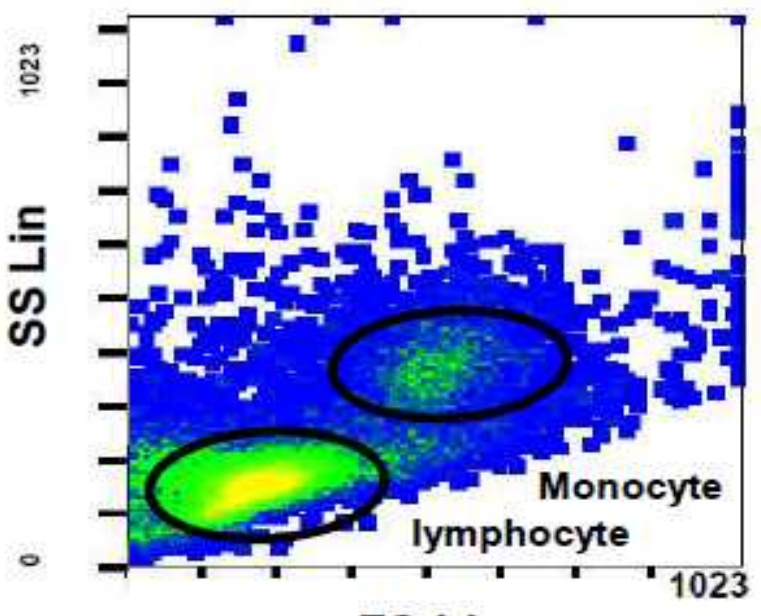

FS Lin

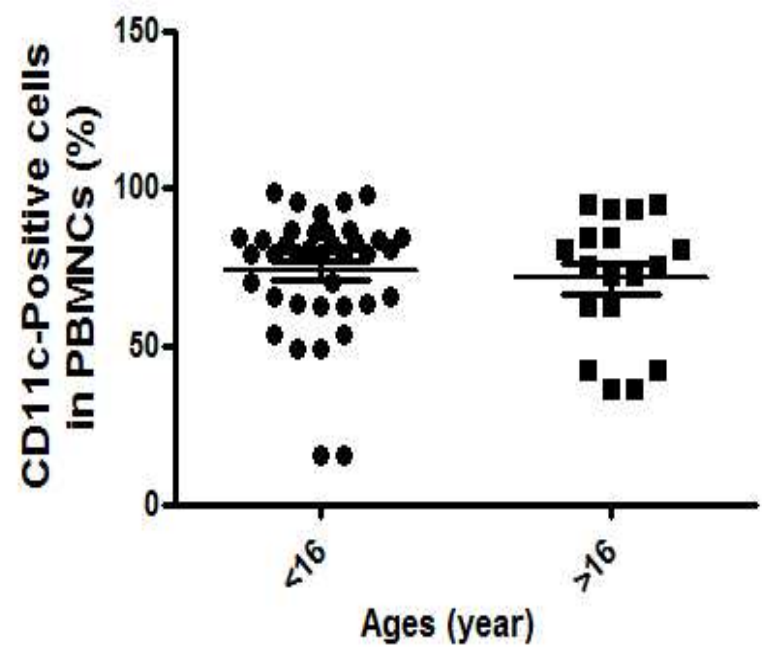

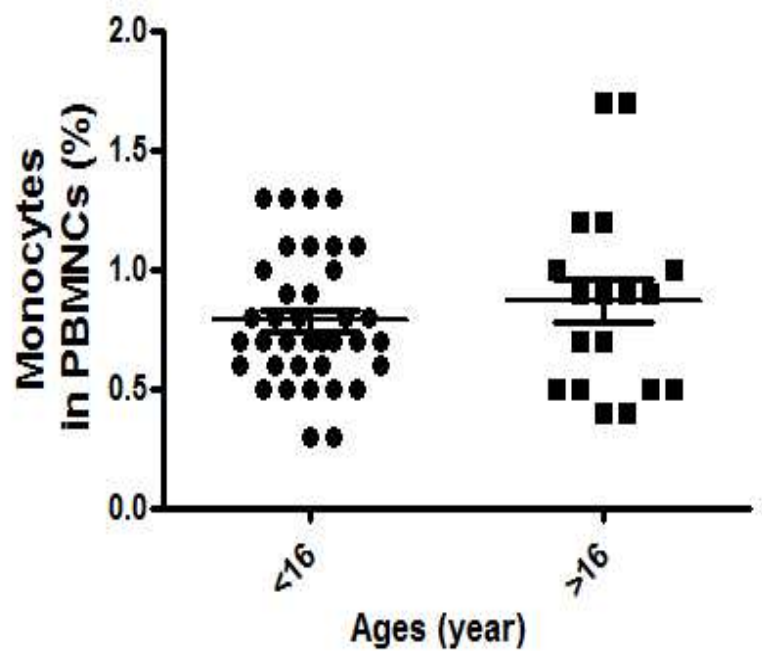

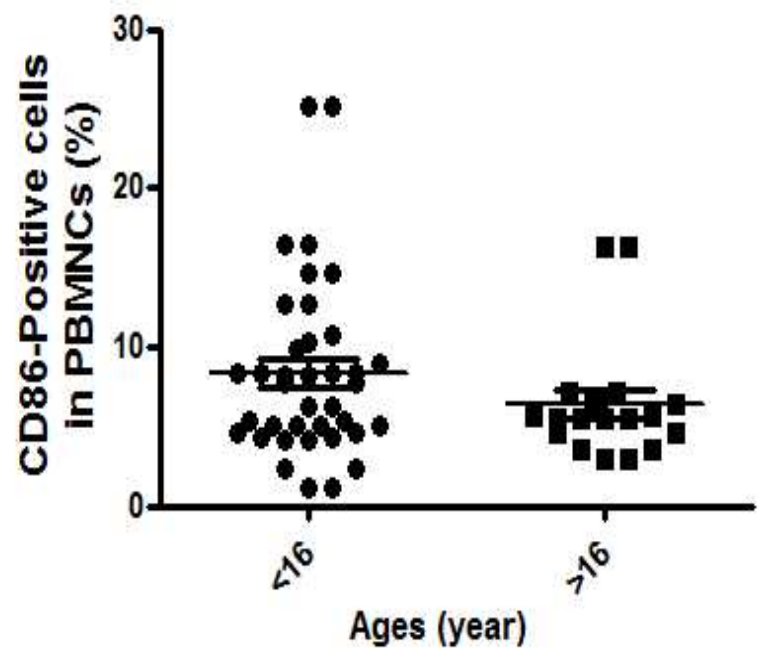

Each level from peripheral blood mononuclear cells with hypertrophy 